\title{
Estrogen and antiestrogen-dependent regulation of breast cancer cell proliferation in multicellular spheroids: Influence of cell microenvironment
}

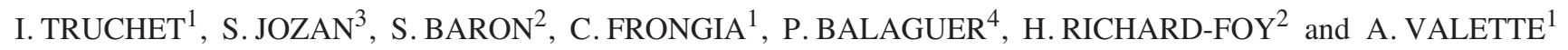 \\ Laboratoires de ${ }^{1}$ Biologie Cellulaire et Moléculaire du Contrôle de la Prolifération (LBCMCP), UMR 5088, ${ }^{2}$ Biologie Moléculaire \\ Eucaryote (LBME), CNRS UMR 5099, Institut d'Exploration Fonctionnelle des Génomes (IFR 109), University of Toulouse, \\ 118 Route de Narbonne; ${ }^{3}$ Laboratoire d'Histologie-Embryologie, Faculté de Medecine Toulouse-Rangueil, \\ 133 Route de Narbonne, 31062 Toulouse Cedex; ${ }^{4}$ Signalisation Hormonale, Environnement et Cancer, \\ INSERM U824 CRCM CRLC Val d'Aurelle, Parc Euromedecine, F34298 Montpellier, Cedex 5, France
}

Received October 2, 2007; Accepted December 3, 2007

\begin{abstract}
Multicellular tumor spheroids, an in vitro 3-D model that simulates malignant-cell contacts within a tumor, can be used to evaluate tumor response to therapeutic agents. We found that MELN (derived from MCF-7 cells) cells grown in 3-D as spheroids, remain highly sensitive to estradiol in terms of growth, down-regulation of ER $\alpha$ expression and ER $\alpha$ induced transcriptional activity. Estradiol induces cyclin D1 and $\mathrm{CDK} 1$ proteins in $\mathrm{Ki}-67$ positive proliferating cells, whereas survivin is up-regulated in both $\mathrm{Ki}-67$ positive proliferative outer layer of cells and around the necrotic zone in non-proliferating cells. OH-Tam inhibits both estradiolinduced transcriptional activity and estradiol-dependent growth of MELN spheroids. Consistent with its antiproliferative effect, we observed that $\mathrm{OH}$-Tam induces an important decrease in the proportion of proliferating cells, positive for Ki-67, cyclin D1 and CDK1. But, in contrast to what was expected, $\mathrm{OH}-\mathrm{Tam}$ treatment resulted in a decrease in the proportion of p21 positive cells. Furthermore, despite its ability to downregulate survivin in MELN spheroids, $\mathrm{OH}$-Tam did not trigger apoptosis. Taken together, these results indicate that this model, is more relevant to an in vivo situation than monolayer cultures. It could be useful to identify new markers of the response to endocrine treatment and to investigate the effects of drugs combination.
\end{abstract}

Correspondence to: Dr A. Valette, LBCMCP, UMR CNRS 5088, University of Toulouse, 118 Route de Narbonne, 31062 Toulouse Cedex, France

E-mail: valette@cict.fr

Key words: hormone-dependent breast cancer, spheroid, antiestrogen, microenvironment

\section{Introduction}

Malignant progression, resulting from genetic changes of cancer cells, is influenced by tumor microenvironment. Cellcell interactions (including malignant-cell interactions) are important modulators of malignant cell phenotype. Normal breast epithelial cells form polarized acini in 3-D culture, while under the same culture conditions, breast cancer cells fail to generate acini structures. Reversal of this malignant phenotype may be observed in 3-D cultures, when using an anti- 31 integrin blocking antibody, but it was never obtained with breast cancer cells cultured in 2-D $(1,2)$. Tissue architecture also regulates sensitivity to exogenous apoptotic stimuli. Multicellular spheroids generated from cancer cells are a good model to investigate the influence of malignant cellinteractions (an aspect of tumor cell microenvironment) on cellular proliferation, differentiation, apoptosis and gene expression. Furthermore, multicellular spheroids could be used to investigate markers of treatment with antitumoral agents. Upon growth, spheroids display a gradient of proliferating cells (3). These proliferating cells are located in the outer cell-layers and the quiescent cells, are located more centrally. When the central cells become deprived in oxygen and glucose, cell death and necrosis occur. This cell heterogeneity is similar to that found in avascular microregions of tumors.

Although the hormone-dependent growth of ER $\alpha$ positive breast adenocarcinoma cell spheroids has been described previously $(4,5)$, scarce data are available regarding how the mechanisms regulating proliferation induced by estrogens and anti-estrogens operate in a multicellular environment. Estradiol bound to its receptor $\mathrm{ER} \alpha$ is a potent mitogen in hormone-dependent breast carcinoma cells. Using standard 2-D culture, it has been shown that the stimulatory effect of estrogens on cell cycle progression in G1 is mediated by the activation of CDK4 and CDK2. The increase in activity of CDK4 results from an increased expression of its regulatory subunit cyclin D1, whereas redistribution of p21 and p27 
CDK inhibitors results in the activation of the cyclin E/CDK2 complex (6-8). Gene profiling analysis (9) have shown that the estrogen-induced cell cycle progression is also associated with the up-regulation of cyclin A2 and CDK1 mRNA levels. In addition, estrogens may also influence cell survival through up-regulation of the antiapoptotic gene, survivin (9). p21 and p27 are required for G1 arrest induced by $\mathrm{OH}-\mathrm{Tam}$ (10) whereas ectopic expression of cyclin D1 abrogates this anti-estrogen cell cycle effect (11).

In the present study, using a multicellular tumor spheroid model, we show that breast cancer cells cultured in 3-D are highly sensitive to estradiol and that their location within the spheroid influences their response to $17-\beta$-estradiol and to $\mathrm{OH}$-Tam, mimicking the situation in avascular regions of breast tumors.

\section{Materials and methods}

Cell line and tissue culture. MELN cells are a clone derived from the breast adenocarcinoma MCF-7 cells. They express the luciferase gene under the control of a synthetic estrogeninducible promoter (12). Cells were grown in DMEM/F12Glutamax $^{+}$media (Gibco) containing $4.5 \mathrm{~g} / 1$ glucose, $50 \mu \mathrm{g} /$ $\mathrm{ml}$ gentamycin and supplemented with $10 \%(\mathrm{v} / \mathrm{v})$ of heat inactivated fetal calf serum. Culture was performed at $37^{\circ} \mathrm{C}$ in a humidified atmosphere containing $5 \% \mathrm{CO}_{2}$. To study the effect of estrogens, cells were switched to media without phenol red and containing serum, stripped of endogenous steroids by three successive incubations with dextran-coated charcoal.

Generation of spheroids. We have adapted the hanging-drop method (13) to produce MELN spheroids of similar diameter. Drops $(25 \mu 1)$ containing 500 cells were suspended on the lid of agar coated 24-well dishes containing $1 \mathrm{ml}$ of culture media. After the $48 \mathrm{~h}$ required for cell aggregation the spheroids were transferred to the culture medium.

Spheroid growth quantification. The size of each spheroid was determined by measuring 2 orthogonal diameters (d1 and d2) using an inverted microscope fitted with a calibrated eye piece reticule. Volume was determined according to the formula: $\mathrm{V}=4 / 3 \pi \mathrm{r} 3$ where $\mathrm{r}=1 / 2 \sqrt{\mathrm{d} 1} \mathrm{xd} 2$.

Luciferase assays. MELN cells grown as monolayers or spheroids were lysed in $200 \mu 1$ Promega lysis buffer and frozen. Protein content of the samples was determined using the AmidoSchwarz technique (14), and an equal amount of protein was used for luciferase activity measurement in all the samples. Luciferase activities were determined using the Luciferase Assay Reagent (Promega ref E397A) in a centro LB 960 (Berthold).

Western blots. Spheroids were rinsed with PBS and lysed in Tris $50 \mathrm{mM}$, pH 6.8, SDS 2\%, glycerol 10\%, ß-mercaptoethanol $5 \%$ and bromophenol blue $0.05 \%$. Protein concentration was determined as described (14) and $100 \mu \mathrm{g}$ of protein was resolved by SDS-polyacrylamide gel electrophoresis and transferred to nitrocellulose membrane by semidry blotting. The membranes were hybridized with anti-ER $\alpha$ antibody $\mathrm{HC} 20$.
Immunohistochemistry. Spheroids were rinsed with PBS and fixed in 10\% neutral-buffered formalin (Sigma) for $3 \mathrm{~h}$ and then paraffin embedded. Sections $(4-\mu \mathrm{m})$ were prepared (ChemMate capillary gap microscope slides, Dakocytomation, Trappes, France). The slides were deparaffinized and progressively rehydrated. Before incubation with the primary antibody they were subjected to antigen retrieval in $10 \mathrm{mM}$ citrate buffer $(\mathrm{pH}$ 6.8) for $2 \times 5$ min. Sections were incubated with the antibodies, overnight at $4^{\circ} \mathrm{C}$ for survivin antibody, and for $1 \mathrm{~h}$ at room temperature for the others primary antibodies and then rinsed. Antigens were revealed using the streptavidin-biotin LSAB2 ${ }^{+}$kit (Dakocytomation) according to the manufacturer's instructions. The primary antibodies were used as follows: mouse monoclonal anti-p21 antibody (Oncogene research products, Cambridge MA; 1/100), anticyclin D1 (Sigma; 1/300), anti-Ki-67 (Dakocytomation; 1/50), anti-p27 (Pharmingen, 1/200) anti-CDK1 (Cell Signaling 1/100), anti-ER $\alpha$ (a generous gift of G. Delsol, 1/20) and anti-survivin (Santa Cruz, 1/50).

TUNEL staining. TUNEL staining was carried out on frozen sections of MELN spheroids. After fixation of MELN spheroids for $3 \mathrm{~h}$ in $10 \%$ neutral-buffered formalin (Sigma), they were rinsed two times in PBS for $10 \mathrm{~min}$. Spheroids were transferred for $12 \mathrm{~h}$ into $15 \%$ sucrose and then stored in $30 \%$ sucrose. They were embedded in tissue teck, frozen and $12 \mu \mathrm{m}$ sections were prepared on a cryostat (Microm). Detection of apoptosis with direct immunofluorescence staining using the ability of TdT to incorporate biotin-dUTP to 3 '-OH ends of DNA beaks was carried out as previously described (15).

\section{Results}

Estradiol-dependent growth of MELN spheroids. Growth of MELN cell spheroids was measured in the presence or the absence of estradiol. As shown in Fig. 1A, the average volume of spheroids maintained in the presence of $1 \mathrm{nM}$ estradiol increased exponentially with respect to time, between approximately days 4 and 21, whereas spheroids cultured in absence of estradiol did not grow significantly ( $<4$-fold in 28 days). Immunohistochemical staining of the proliferation marker Ki-67 (16) on sections of MELN spheroids embedded in paraffin clearly shows that in the presence of $1 \mathrm{nM}$ estradiol most of Ki-67 positive cells are found on the outside of the spheroids whereas few Ki-67 positive cells are found at the center of the spheroids indicating that the hormone induces a gradient of proliferation within the spheroids (Fig. 1B). A limited number of Ki-67 proliferative cells were observed in MELN spheroids maintained in culture in the absence of estradiol (Fig. 1B).

To further explore the regulation of hormone-dependent proliferation of breast cancer cells in 3-D culture we compared estrogen receptor levels, in protein extracts from different pools of spheroids, by Western blot analysis. Those grown in the presence of $1 \mathrm{nM}$ estradiol contained much lower levels of ER $\alpha$ than those maintained in absence of estradiol (Fig. 2A). This result was further confirmed by ER $\alpha$ immunohistochemical staining (Fig. 2B). Most of the cell nuclei were positive for $\mathrm{ER} \alpha$ in spheroids maintained in the absence of 
A)

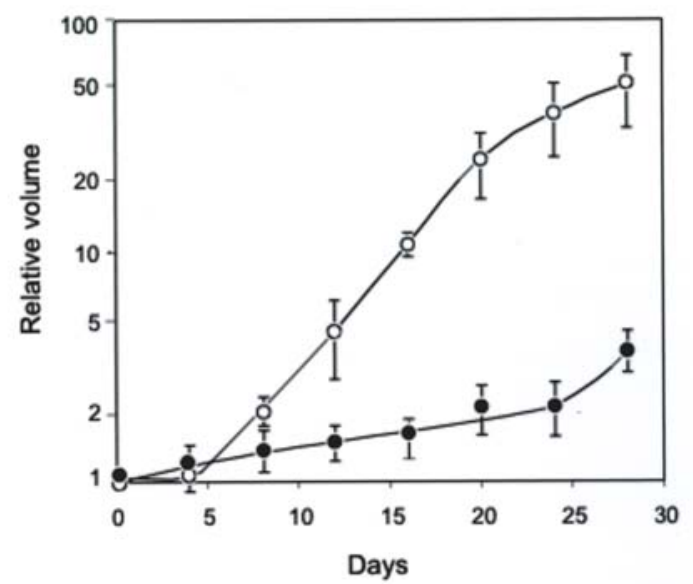

B) $\mathrm{Ki}-67$
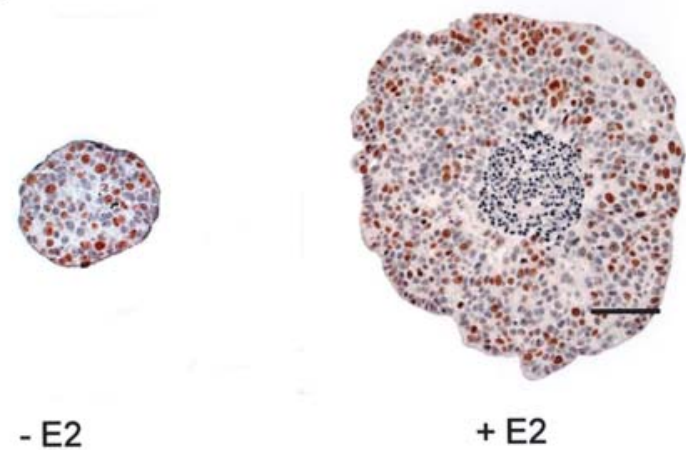

Figure 1. Growth hormone-dependence of MELN spheroids. (A) The MELN multicellular tumor spheroids were grown in the presence (O) or absence $(\bullet)$ of estradiol $1 \mathrm{nM}$. The volume of each spheroid was measured the day of culture initiation and at the indicated day. Spheroid diameter the day of culture initiation was around $20 \mu \mathrm{m}$. Each point is the mean $\pm \mathrm{SD}$ of three different experiments and in each experiment the volumes of at least 4 spheroids were measured. The relative spheroid volume (ratio of the volume of the spheroids at day n, over the volume of the spheroids at day 0 ) is plotted as a function of time. (B) Expression and distribution of Ki-67 in MELN spheroids maintained in presence or absence of 17- $\beta$ estradiol for 21 days. The scale bars corresponds to $100 \mu \mathrm{m}$. estradiol, while staining intensity and number of stained nuclei were dramatically decreased in spheroids grown in the presence of $1 \mathrm{nM}$ estradiol. This down-regulation of $\mathrm{ER} \alpha$, induced by estradiol, was independent of the position of cells within the spheroid.

OH-Tam inhibits estradiol effects on MELN spheroids. The expression of the luciferase gene under the control of an estrogen receptor responsive element in MELN cells allowed measuring the effect of estradiol and of the antiestrogen $\mathrm{OH}-\mathrm{Tam}$ on the expression of the luciferase reporter gene integrated to the host cell genome. We observed that $1 \mathrm{nM}$ $17-\beta$-estradiol induced a 50-fold increase in ER $\alpha$-dependent luciferase activity in MELN cells grown as spheroids (Fig. 3A). This induction of luciferase expression, which represents an estradiol-induction of gene expression 2.5-fold higher than obtained when the cells were grown as monolayers (data not shown), was abolished in the presence of a 100-fold excess OH-Tam.

The addition, for 6 days, of various concentrations of $\mathrm{OH}-$ Tam 12 days after spheroid culture initiation, caused a dosedependent inhibition of MELN spheroid growth with an $\mathrm{IC}_{50}$ of $33 \mathrm{nM}$ (Fig. 3B). In contrast to what is commonly observed for chemotherapeutic agents, the efficacy of $\mathrm{OH}-\mathrm{Tam}$ in this 3-D model of breast cancer cells is similar to that measured for MELN cells grown as monolayers $\left(\mathrm{IC}_{50}=20 \mathrm{nM}\right.$, data not shown). These results indicate that MELN spheroids remain highly sensitive to the antagonist effects of OH-Tam. To further characterize the inhibition of $\mathrm{OH}-\mathrm{Tam}$-induced spheroid growth, they were first cultured for 15 days in the presence $1 \mathrm{nM}$ estradiol, then treated or not with OH-Tam $(100 \mathrm{nM})$ for 6 days and immunostained for the proliferation marker Ki67. A 6-day treatment of MELN spheroids with OH-Tam induced substantial decrease in the proportion of Ki-67 positive cells (Fig. 3C), confirming a growth inhibition of the spheroids by $\mathrm{OH}-\mathrm{Tam}$.

OH-Tam regulated cell cycle machinery in MELN spheroids. We then investigated how estradiol and $\mathrm{OH}$-Tam modulate

A)

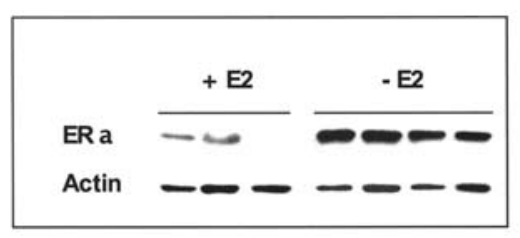

$+\mathrm{E} 2$

B)

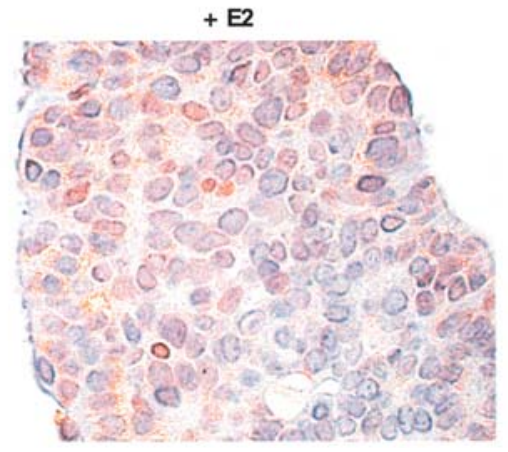

- E2

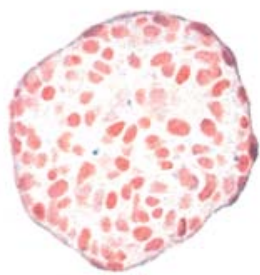

Figure 2. Effect of estradiol on ER $\alpha$ expression in MELN spheroids. Spheroids were maintained for 15 days in the absence or presence of 1 nM estradiol and ER $\alpha$ expression was analyzed by Western blot (panel A) or immunohistochemistry (panel B). 
A)

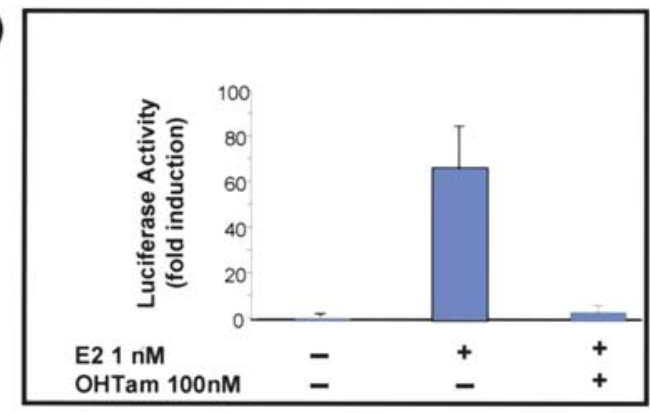

C) $\mathrm{Ki67}$

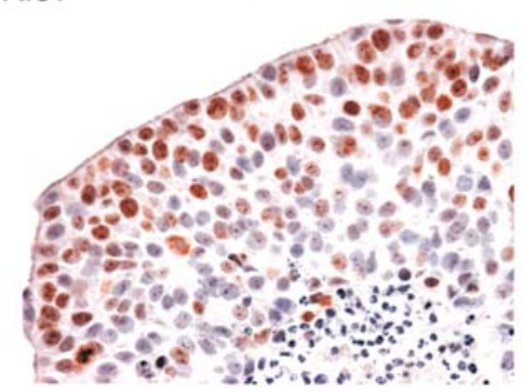

B)

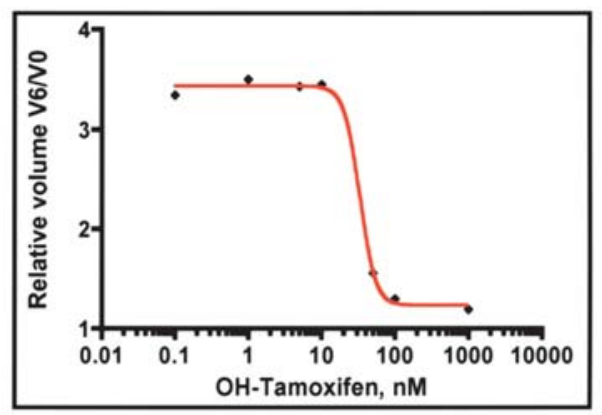

$\mathrm{OH}-\mathrm{Tam} 100 \mathrm{nM}$

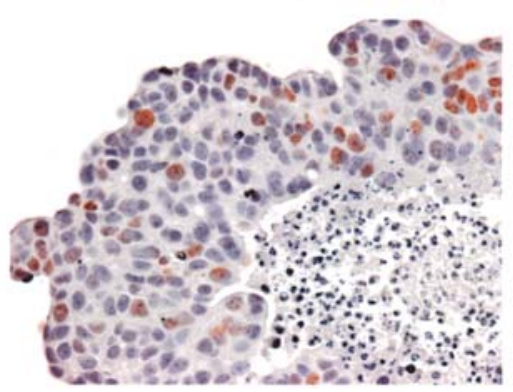

Figure 3. Effect of OH-Tam on the responses of MELN spheroids to estradiol. (A) The estradiol-induced luciferase activity was measured in extracts prepared from MELN spheroids maintained for 15 days in the absence (control) or in the presence of $1 \mathrm{nM}$ estradiol. OH-Tam (100 nM) was added to the culture media containing estradiol for the last $24 \mathrm{~h}$. Results are expressed as the induction fold, relative to the untreated spheroids. (B) Spheroids were grown for 15 days in the presence of $1 \mathrm{nM}$ estradiol, increasing concentrations of OH-Tam were added for a 6-day additional period. The size of the spheroids was measured. The relative volume corresponds to the ratio of the volume of the spheroids 6 days after OH-Tam treatment over the volume of the spheroids at the time of OH-Tam addition. In the two panels, results represent the mean \pm SD of 3 experiments. In each experiment, at least 10 spheroids were used in panel A and 4 spheroids in panel B. (C) Expression and distribution of Ki-67 in MELN spheroids maintained in the presence or absence of OH-Tam, $100 \mathrm{nM}$ for 6 days.

cell cycle machinery to regulate this proliferation gradient. Cyclin D1 is one of the mediators of $17-\beta$-estradiol mitogenic effect. We observed (Fig. 4) that at the periphery of the spheroids a high proportion of the cells were positive for cyclin D1. This proportion decreases going towards the center of the spheroid, cyclin D1 expression following that of the proliferation marker, Ki-67. In presence of OH-Tam a decrease in the proportion of cyclin D1 positive cells was found (Fig. 4). It has been shown that $C d k l$ gene expression is stimulated by estradiol (9). However, little is known regarding the hormonedependent regulation of CDK1 protein. Immunohistochemical staining indicated that $\mathrm{OH}-\mathrm{Tam}$ induces a decrease in the proportion of CDK1 positive cells compared to that observed in presence of 17-ß-estradiol (Fig. 4). This is to our knowledge the first evidence that OH-Tam regulates CDK1 protein expression. p21 an inhibitor of CDKs was only detected in nuclei of a few cells within the spheroids. These cells were distributed throughout the spheroids in proliferating as well as in quiescent cells. p21 immunoreactivity was markedly decreased in OH-Tam-treated MELN spheroids. Besides stimulating tumor cell proliferation, estradiol increases cell survival through up-regulation of various antiapoptotic genes. Stimulation of mRNA synthesis of one of these genes, survivin, has been described in gene profiling experiments (9). Western blot analysis (data not shown) confirmed that, in MELN spheroids, survivin is induced by estradiol at the protein levels. Immunohistochemical staining revealed that estradiol-induced survivin expression was not only observed in proliferating cells but also in quiescent cells. Indeed, survivin positive cells being observed throughout the entire spheroid, with a preference, for cells located near the necrotic zone (Fig. 4). In addition, Fig. 4 shows that in the presence of hormone, cyclin D1 and p21 were essentially localized in the nucleus of MELN cells growing as spheroids, while survivin was detected in the nucleus or in the cytoplasm or both.

OH-TAM does not induce apoptosis in MELN spheroids. Since OH-TAM induces substantial down-regulation in survivin expression we investigated if its inhibitory effect on MELN spheroid growth results or not from an induction of apoptosis. Apoptotic cells were labeled by TUNEL staining on frozen section of control and OH-Tam-treated MELN spheroid. Few apoptotic cells were observed in the center of control MELN spheroids. Ninety-six hours after treatment with OH-Tam $(100 \mathrm{nM}$ and $1 \mu \mathrm{M})$, the proportion of apoptotic cells did not increase significantly, suggesting that the ability of OH-TAM to inhibit MELN spheroid growth does not result from an induction of apoptosis (Fig. 5).

\section{Discussion}

Here we have prepared spheroids from the breast cancer cell line MELN, estrogen-dependent for its growth, using a hanging-drop method, which allows obtaining a homogeneous population of spheroids. We have characterized the hormone- 
Control

\section{Cyclin D1}

CDK1

p21
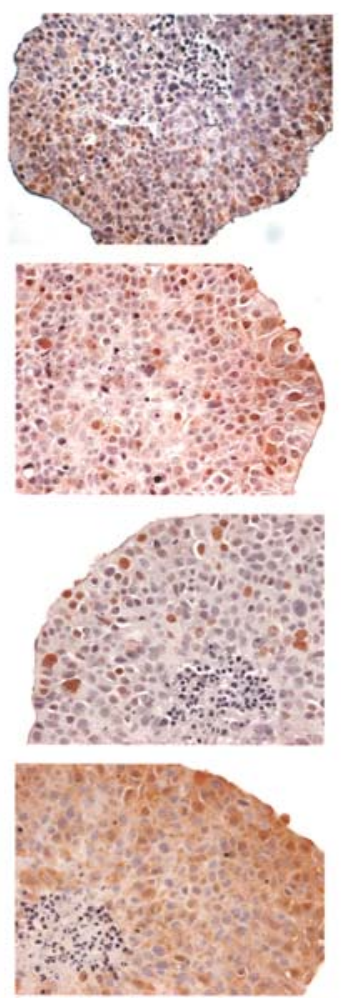
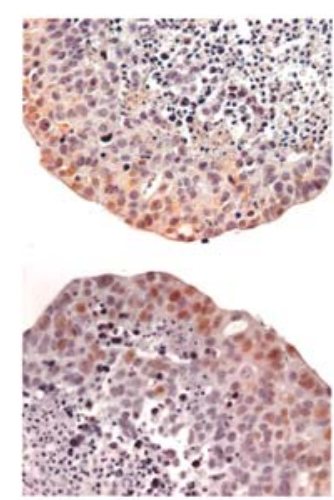

OH-Tam,100nM
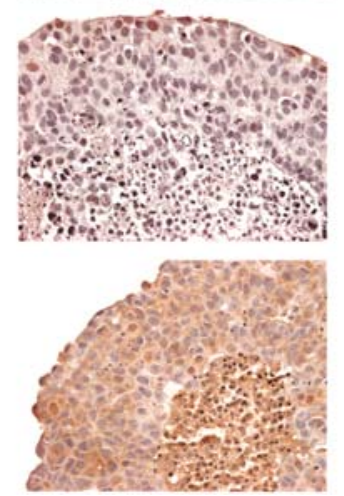

Figure 4. Effect of OH-Tam on expression and distribution of cyclin D1, CDK1, p21 and survivin in MELN spheroids. Spheroids were grown for 15 days in the presence of $1 \mathrm{nM}$ estradiol and then treated for 6 days with $100 \mathrm{nM}$ $\mathrm{OH}-\mathrm{Tam}$.

dependent growth response of these MELN spheroids. We found that MELN cells in 3-D culture remained highly sensitive to estradiol in terms of growth, down-regulation of $\mathrm{ER} \alpha$ expression and induction of ER $\alpha$ transcriptional activity. OH-Tam inhibits both estradiol-induced MELN spheroid growth and ER $\alpha$-induced transcriptional activity. Furthermore, our results underscore the importance of cancer cell microenvironment in their responses to estradiol and OH-Tam.

The growth of MELN spheroids is strictly dependent on the presence of estradiol in the culture medium, thus repro- ducing in vitro what is observed in vivo when human hormonedependent cancer cell lines are xenografted in nude mice. We detected high levels of ER $\alpha$ in almost all cells when the spheroids were maintained in absence of estradiol. In contrast, substantial down-regulation of ER $\alpha$ expression was observed after long-time exposure of MELN spheroids to estradiol. This was expected since regulation of ER $\alpha$ levels by estradiol appears to be a complex process involving both transcriptional (17) and post-transcriptional mechanisms (18). $\mathrm{Ki}-67$ staining reveals that in the presence of estradiol, a spatial gradient of proliferation takes place within the spheroids. OH-Tam induces a dose-dependent inhibition of MELN spheroid growth. According to previous observations (4), our results indicate that $\mathrm{OH}-\mathrm{Tam}$ is as effective in inhibiting MELN spheroid growth as in inhibiting MELN monolayer cell culture. This observation suggests that the multicellular mechanism of resistance, which is well established for numerous therapeutic agents (19-21), is not a major mechanism of resistance to tamoxifen. The antigrowth effect of OH-Tam on MELN spheroids is correlated with an important decrease in the proportion of the Ki-67 positive proliferating cells, whereas no significant increase in the basal level of apoptosis was detected. This agrees with clinical observations showing that short-term changes in Ki67 levels are predictive markers of outcome during neoadjuvant endocrine therapy of breast cancer. In addition, under the same conditions, basal level of apoptosis does not significantly change after tamoxifen treatment (22). Taken together these data suggest that the spheroid model could be useful to identify and allow a preliminary validation of new markers of response of breast cancer cells to OH-Tam.

The estrogens dependency of breast cancer cell proliferation and the cytostatic effect of antiestrogens result from the ability of these compounds to modulate cell progression through the G1 phase of the cell cycle. While estradiol induces cyclin D1 expression, antiestrogens have an opposite inhibitory effect. In addition to up-regulating cyclin D1, estrogens also elicit activation of cyclin E/CDK2 through p21 redistribution (6). Little is known concerning the hormone-dependent regulation of the cell cycle machinery in a 3-D context. Here, we found that in the presence of estradiol, cyclin D1 expression

TUNEL

Control

$100 \mathrm{nM}$

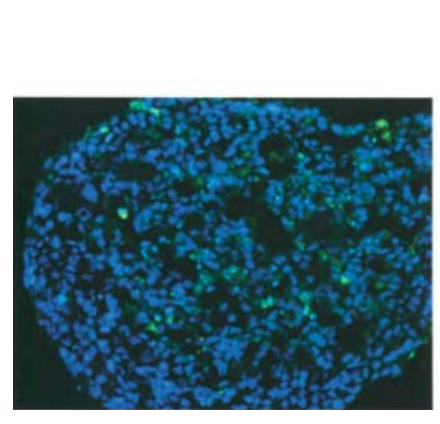

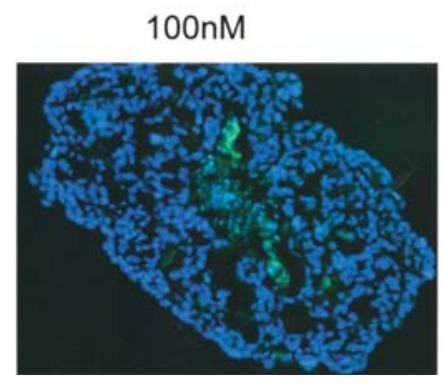

OH-TAM

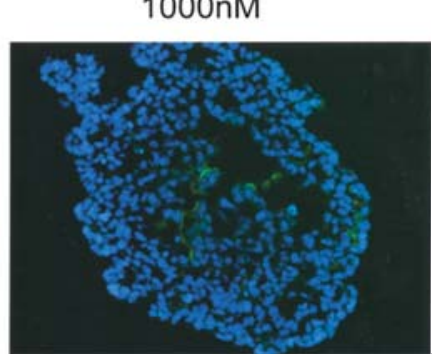

Figure 5. Effect of OH-Tam on the proportion and the distribution of TUNEL positive cells in MELN spheroids. Spheroids were grown for 15 days in the presence of $1 \mathrm{nM}$ estradiol and then treated for 6 days with $100 \mathrm{nM}$ or $1 \mu \mathrm{M} \mathrm{OH}-\mathrm{Tam}$. 
was restricted mainly to the outer cell layer, with a decrease in the proportion of positive cells towards the center of the spheroid. This indicates that in the presence of estradiol cyclin D1 expression follows the gradient of proliferation confirming in the 3-D context that cyclin D1 expression is the major mechanism of hormone-dependent regulation of breast cancer cells proliferation. Gene profiling experiments have shown that, in addition to cyclin D1, estrogens upregulate the level of CDK1 kinase (9), which is responsible for the $\mathrm{G} 2 / \mathrm{M}$ transition, through its association with cyclin B. Little is known concerning the estrogen-dependent regulation of CDK1 at the protein level. Cells positive for CDK1 in estradiol-treated spheroids follow the gradient of proliferation, suggesting that the up-regulation of this kinase by itself may participate in the stimulatory effect of estradiol on breast cancer cell proliferation. We found that, in the presence of estradiol, the inhibitor of CDKs p21 is expressed mainly in proliferating cells. This is in agreement with a previous report on melanoma and mouse mammary carcinoma spheroids (23). This p21 distribution could reflect other p21 functions, such as its ability to promote the assembly of cyclin D1/ CDK4 complexes (24), leading to cell cycle progression or acting as a positive modulator of cell survival (25). Survivin is a bifunctional protein that acts as a suppressor of apoptosis and also has an essential role in regulating negatively mitosis progression (26). In breast cancer cells, expression of survivin is regulated by coexpression of EGF receptor and HER2 (27), bFGF can also mediate survivin expression through the transcriptional factor c-myc (28). Inhibition of Her2 signaling leads to a marked inhibition of survivin expression with subsequent apoptosis (29). Furthermore, it has been recently shown that ER $\alpha$ binds to p53 on survivin gene promoter leading to inhibition of p53-mediated repression of this gene and that RNAi-mediated knockdown of ER $\alpha$ results in reduced survivin and enhanced apoptosis in response to staurosporine (30). We showed that in MELN spheroids growing in the presence of estradiol, survivin is expressed thoughout the spheroid but a high proportion of positive cells are located close to the central necrotic zone. At the subcellular level, survivin was detected in the nucleus or in the cytoplasm or both. This agrees with previous observations indicating that survivin exists in two subcellular pools, cytoplasmic and nuclear (31). Nuclear survivin was suspected to control cell division, whereas cytoplasmic survivin was considered to be a survival factor (34).

The question arises whether such estrogen-regulated proteins could be potential markers of antiestrogen effect. We observed that the substantial decrease in both cyclin D1 and CDK1 positive cells correlated well with the OH-Tam antiproliferative effect of $\mathrm{OH}$-Tam suggesting that, in addition to $\mathrm{Ki}-67$, these two cell cycle regulators could be markers of $\mathrm{OH}-\mathrm{Tam}$ response. The down-regulation of survivin expression observed in OH-Tam-treated MELN spheroids was not correlated with an induction of apoptosis suggesting that down-regulation of survivin is not sufficient for OH-Tam to trigger apoptosis. The question arises of a potential correlation between the cytostatic effect of $\mathrm{OH}-\mathrm{Tam}$ and the down-regulation of survivin. Indeed, in addition to its role in cell cycle progression through mitosis, it has been shown that survivin modulated cell cycle entry by competitive interactions with CDK4 and CDK2 complexes (32) and that survivin up-regulation by growth factors is an early event in cell cycle entry for hematopoietic stem and progenitor cells (33). Furthermore it has also been shown that vitamin D3 induced survivin down-regulation is essential for Vitamin D3-mediated growth arrest (34). The hypothesis that survivin could play a role in the G1 phase of the cell cycle in response to estradiol and $\mathrm{OH}-\mathrm{Tam}$ is now under investigation. Survivin is an independent predictor of short-term survival in poor prognostic breast cancer patients (35), it could be also a predictive factor of $\mathrm{OH}-\mathrm{Tam}$ response during neoadjuvant hormone therapy. It has been previously shown that in MCF-7 cells cultured as monolayers, the level of p21 increases after antiestrogen treatment and this increase correlates with inhibition of CDK4 activity (36). In addition, down-regulation of p21 abrogates antiestrogen-mediated cell cycle arrest in human breast cancer cells (10). We found that a 6 daytreatment of MELN spheroids with $\mathrm{OH}$-Tam induced substantial decrease in p21 indicating that at this time the decrease in Ki-67 positive proliferating cells is associated with a 21 decrease rather than with its increase, as shown in the monolayer. A decrease in $\mathrm{p} 21$ has also been described a 3 -D spheroids, as cells become quiescent (23), these authors also showed that regulation of cyclin-dependent kinase inhibitor differs in monolayer versus spheroid culture (37). An association between a decrease in p21 and a decrease in the proliferation index has also been previously observed after androgen deprivation of androgen-dependent prostate cancer cells xenografted on nude mice (38). These data allow to make the hypothesis that a decrease rather than an increase in $\mathrm{p} 21$ could be a marker for long-term antiestrogen response in breast carcinoma cells.

Taken together these results argue in favor of the important role of cancer cell microenvironment in their response to antiestrogens. Furthermore, this 3-D model can be very useful to study hormone-dependent breast cancer cell proliferation and to identify new markers of response to hormone therapy. This model allows investigating the effect of a drug and to visualize it in different cell populations within a region of the spheroid, a model more relevant to the in vivo situation than 2 -D cell cultures. It should be particularly useful to analyze the effects of drug-combination therapies, which are difficult to perform in details in animal models, because they are expensive and time-consuming and also raise ethical concerns regarding use of animals.

\section{Acknowledgements}

We thank Viviane Blanco for assistance in the histochemistry experiments. This study was partially supported by La Ligue Contre le Cancer du Tarn et Garonne et de Midi-Pyrénées, Association pour la Recherche contre le Cancer and Institut National du Cancer, contract \#PL06_045.

\section{References}

1. Wang F, Hansen RK, Radisky D, Yoneda T, Barcellos-Hoff MH, Petersen OW, Turley EA and Bissell MJ: Phenotypic reversion or death of cancer cells by altering signaling pathways in threedimensional contexts. J Natl Cancer Inst 94: 1494-1503, 2002

2. Weaver VM, Petersen OW, Wang F, Larabell CA, Briand P, Damsky $\mathrm{C}$ and Bissell MJ: Reversion of the malignant phenotype of human breast cells in three-dimensional culture and in vivo by integrin blocking antibodies. J Cell Biol 137: 231-245, 1997. 
3. Sutherland RM: Cell and environment interactions in tumor microregions: the multicell spheroid model. Science 240: 177-184, 1988.

4. Muller-Holzner E, Marth C, Zeimet AG, Hofstadter F and Daxenbichler G: Effects of sex- and glucocorticoid steroids on breast cancer cells grown as either multicellular tumor spheroids or monolayers. J Steroid Biochem Mol Biol 58: 13-19, 1996.

5. Olea N, Villalobos M, Nunez MI, Elvira J, Ruiz de Almodovar JM and Pedraza V: Evaluation of the growth rate of MCF-7 breast cancer multicellular spheroids using three mathematical models. Cell Prolif 27: 213-223, 1994.

6. Planas-Silva MD and Weinberg RA: Estrogen-dependent cyclin E-cdk2 activation through p21 redistribution. Mol Cell Biol 17: 4059-4069, 1997.

7. Prall OW, Rogan EM, Musgrove EA, Watts CK and Sutherland RL: c-Myc or cyclin D1 mimics estrogen effects on cyclin E-Cdk2 activation and cell cycle reentry. Mol Cell Biol 18: 4499-4508, 1998

8. Prall OW, Sarcevic B, Musgrove EA, Watts CK and Sutherland RL: Estrogen-induced activation of Cdk4 and Cdk2 during G1-S phase progression is accompanied by increased cyclin D1 expression and decreased cyclin-dependent kinase inhibitor association with cyclin E-Cdk2. J Biol Chem 272: 10882-10894, 1997.

9. Frasor J, Danes JM, Komm B, Chang KC, Lyttle CR and Katzenellenbogen BS: Profiling of estrogen up- and downregulated gene expression in human breast cancer cells: insights into gene networks and pathways underlying estrogenic control of proliferation and cell phenotype. Endocrinology 144: 4562-4574, 2003

10. Cariou S, Donovan JC, Flanagan WM, Milic A, Bhattacharya N and Slingerland JM: Down-regulation of p21WAF1/CIP1 or p27Kip1 abrogates antiestrogen-mediated cell cycle arrest in human breast cancer cells. Proc Natl Acad Sci USA 97: 9042-9046, 2000

11. Hui R, Finney GL, Carroll JS, Lee CS, Musgrove EA and Sutherland RL: Constitutive overexpression of cyclin D1 but not cyclin $\mathrm{E}$ confers acute resistance to antiestrogens in T-47D breast cancer cells. Cancer Res 62: 6916-6923, 2002.

12. Balaguer P, Boussioux AM, Demirpence E and Nicolas JC: Reporter cell lines are useful tools for monitoring biological activity of nuclear receptor ligands. Luminescence 16: 153-158, 2001.

13. Del Duca D, Werbowetski T and Del Maestro RF: Spheroid preparation from hanging drops: characterization of a model of brain tumor invasion. J Neurooncol 67: 295-303, 2004.

14. Schaffner W and Weissmann C: A rapid, sensitive, and specific method for the determination of protein in dilute solution. Anal Biochem 56: 502-514, 1973 .

15. Lafon C, Mathieu C, Guerrin M, Pierre O, Vidal S and Valette A: Transforming growth factor beta 1-induced apoptosis in human ovarian carcinoma cells: protection by the antioxidant $\mathrm{N}$ acetylcysteine and bcl- 2. Cell Growth Differ 7: 1095-1104, 1996.

16. Endl E and Gerdes J: The Ki-67 protein: fascinating forms and an unknown function. Exp Cell Res 257: 231-237, 2000.

17. Saceda M, Lippman ME, Lindsey RK, Puente M and Martin MB: Role of an estrogen receptor-dependent mechanism in the regulation of estrogen receptor mRNA in MCF-7 cells. Mol Endocrinol 3: 1782-1787, 1989.

18. Nawaz Z, Lonard DM, Dennis AP, Smith CL and O'Malley BW: Proteasome-dependent degradation of the human estrogen receptor. Proc Natl Acad Sci USA 96: 1858-1862, 1999

19. Desoize B and Jardillier J: Multicellular resistance: a paradigm for clinical resistance? Crit Rev Oncol Hematol 36: 193-207, 2000.

20. Hall MD, Martin C, Ferguson DJ, Phillips RM, Hambley TW and Callaghan R: Comparative efficacy of novel platinum (IV) compounds with established chemotherapeutic drugs in solid tumour models. Biochem Pharmacol 67: 17-30, 2004.

21. Frankel A, Buckman R and Kerbel RS: Abrogation of taxolinduced G2-M arrest and apoptosis in human ovarian cancer cells grown as multicellular tumor spheroids. Cancer Res 57: 2388-2393, 1997.
22. Dowsett M, Smith IE, Ebbs SR, Dixon JM, Skene A, Griffith C, Boeddinghaus I, Salter J, Detre S, Hills M, Ashley S, Francis S and Walsh G: Short-term changes in Ki-67 during neoadjuvant treatment of primary breast cancer with anastrozole or tamoxifen alone or combined correlate with recurrence-free survival. Clin Cancer Res 11: 951s-958s, 2005.

23. LaRue KE, Khalil M and Freyer JP: Microenvironmental regulation of proliferation in multicellular spheroids is mediated through differential expression of cyclin-dependent kinase inhibitors. Cancer Res 64: 1621-1631, 2004.

24. LaBaer J, Garrett MD, Stevenson LF, Slingerland JM, Sandhu C, Chou HS, Fattaey A and Harlow E: New functional activities for the p21 family of CDK inhibitors. Genes Dev 11: 847-86, 1997.

25. Gorospe M, Wang X and Holbrook NJ: Functional role of p21 during the cellular response to stress. Gene Expr 7: 377-385, 1999.

26. Altieri DC: The case for survivin as a regulator of microtubule dynamics and cell-death decisions. Curr Opin Cell Biol 18: 609-615, 2006

27. Asanuma H, Torigoe T, Kamiguchi K, Hirohashi Y, Ohmura T, Hirata K, Sato M and Sato N: Survivin expression is regulated by coexpression of human epidermal growth factor receptor 2 and epidermal growth factor receptor via phosphatidylinositol 3-kinase/AKT signaling pathway in breast cancer cells. Cancer Res 65: 11018-11025, 2005.

28. Cosgrave N, Hill AD and Young LS: Growth factor-dependent regulation of survivin by c-myc in human breast cancer. J Mol Endocrinol 37: 377-390, 2006.

29. Xia F and Altieri DC: Mitosis-independent survivin gene expression in vivo and regulation by $\mathrm{p} 53$. Cancer Res 66 3392-3395, 2006.

30. Sayeed A, Konduri SD, Liu W, Bansal S, Li F and Das GM: Estrogen receptor (alpha) inhibits p53-mediated transcriptional repression: implications for the regulation of apoptosis. Cancer Res 67: 7746-7755, 2007.

31. Fortugno P, Wall NR, Giodini A, O'Connor DS, Plescia J, Padgett KM, Tognin S, Marchisio PC and Altieri DC: Survivin exists in immunochemically distinct subcellular pools and is involved in spindle microtubule function. J Cell Sci 115: 575-585, 2002

32. Suzuki A, Ito T, Kawano H, Hayashida M, Hayasaki Y, Tsutomi Y, Akahane K, Nakano T, Miura M and Shiraki K: Survivin initiates procaspase $3 / \mathrm{p} 21$ complex formation as a result of interaction with Cdk4 to resist Fas-mediated cell death. Oncogene 19: 1346-1353, 2000.

33. Fukuda $S$ and Pelus LM: Elevation of survivin levels by hematopoietic growth factors occurs in quiescent CD34 hematopoietic stem and progenitor cells before cell cycle entry Cell Cycle 1: 322-326, 2002.

34. Li F, Ling X, Huang H, Brattain L, Apontes P, Wu J, Binderup L and Brattain MG: Differential regulation of survivin expression and apoptosis by vitamin D3 compounds in two isogenic MCF-7 breast cancer cell sublines. Oncogene 24: 1385-1395, 2005.

35. Hinnis AR, Luckett JC and Walker RA: Survivin is an independent predictor of short-term survival in poor prognostic breast cancer patients. Br J Cancer 96: 639-645, 2007.

36. Skildum AJ, Mukherjee S and Conrad SE: The cyclin-dependent kinase inhibitor p21WAF1/Cip1 is an antiestrogen-regulated inhibitor of Cdk4 in human breast cancer cells. J Biol Chem 277: 5145-5152, 2002.

37. LaRue KE, Bradbury EM and Freyer JP: Differential regulation of cyclin-dependent kinase inhibitors in monolayer and spheroid cultures of tumorigenic and non-tumorigenic fibroblasts. Cancer Res 58: 1305-1314, 1998

38. Fizazi K, Martinez LA, Sikes CR, Johnston DA, Stephens LC, McDonnell TJ, Logothetis CJ, Trapman J, Pisters LL, Ordonez NG, Troncoso P and Navone NM: The association of p21(WAF-1/CIP1) with progression to androgen-independent prostate cancer. Clin Cancer Res 8: 775-781, 2002. 